\title{
O VALOR DAS DIFERENÇAS NO INVESTIMENTO SOCIAL PRIVADO EM EDUCAÇÃO
}

\author{
Mário Aquino Alves \\ Andréa Martini Pineda
}

\section{// resumo}

Resultados de pesquisas e uma vasta literatura comprovam os ganhos de aprendizagem em escolas mais diversas e equânimes. Relatórios e indicadores apontam uma tendência de aproximação do investimento social privado (ISP) com o setor público. Ao mesmo tempo, a área de educação concentra $84 \%$ dos investidores. Contudo, ao fazer um recorte dos projetos que priorizam a diversidade, apenas $2 \%$ das organizações consideram diferenças raciais e $4 \%$ questões de gênero em seus programas. Este artigo traz a hipótese de que os baixos investimentos em educação com ênfase em diversidade podem estar relacionados ao fato de os conselhos gestores dessas organizações não serem diversos: metade dos institutos e fundações possuem $75 \%$ ou mais de conselheiros homens e $71 \%$ possuem apenas conselheiros brancos. Nesse contexto, este texto buscou refletir sobre como o ISP pode contribuir com a valorização das diferenças nas políticas públicas de educação.

| palavras-chave: Diversidade | Investimento Social Privado | Educação |

Políticas Públicas 


\section{O GIFE}

O Grupo de Institutos Fundações e Empresas (GIFE) é uma organização sem fins lucrativos que reúne associados de origem empresarial, familiar ou independente que investem em projetos de interesse público. Criado em 1989 como grupo de troca e colaboração e institucionalizado em 1995 por 25 organizações, tornou-se referência no campo da filantropia e do investimento social privado no Brasil.

Nesses mais de 20 anos de atuação, tem contribuído para o fortalecimento de práticas e ações a serviço do bem comum no país, trabalhando para expandir, qualificar e fortalecer o investimento social privado, diversificar e ampliar atores e recursos, criando referências e estimulando boas práticas de gestão, bem como articulando o setor com a sociedade e a agenda pública. Atualmente, o GIFE reúne mais de 150 associados que, somados, aportam mais de R 3 bilhões por ano em projetos próprios e no apoio a projetos de terceiros.

\section{OS ARTIGOS GIFE}

A série Artigos GIFE publica reflexões e análises de pesquisadores brasileiros de diferentes áreas do saber com o objetivo de estimular, ampliar e disseminar a produção de conhecimento qualificado sobre o campo da filantropia, do investimento social privado e da sociedade civil no Brasil.

A partir da premissa de que a produção de conhecimento sobre esses temas tem um papel fundamental na expansão, diversificação e qualificação da ação pública pela sociedade, a iniciativa também pretende contribuir para ampliar as conexões entre o setor, as universidades e centros de pesquisa, promovendo e apoiando o envolvimento de novos atores com a temática e a circulação ampliada de ideias em torno dela.

Este artigo integra a primeira edição dos Artigos GIFE que foram selecionados na chamada pública lançada pelo GIFE em 2018, com base na avaliação de um comitê externo. Os textos se enquadram em um dos 16 temas propostos e dialogam com dados do Censo GIFE 2016 ou de pelo menos uma das seguintes pesquisas: BISC 2017, Pesquisa Doação Brasil e Perfil das Organizações da Sociedade Civil no Brasil, conforme estabelecido no edital da chamada.

É com alegria que publicamos os primeiros artigos dessa iniciativa que, a partir de então, se propõe a ser contínua, buscando apoiar e fomentar a produção de conhecimento sobre esse campo no Brasil. 


\section{artigos \\ GIFE}

\section{EDUCAÇÃO E DIVERSIDADE NO INVESTIMENTO SOCIAL PRIVADO}

Conviver com as diferenças potencializa o aprendizado no ambiente escolar. Partindo dessa premissa, este artigo procura discutir o baixo investimento em programas e projetos de valorização da diversidade por institutos e fundações empresariais, sendo a educação a área mais beneficiada por seus investimentos.

Inicialmente, é preciso compreender o próprio conceito de 'diversidade', carregado de tantos significados na literatura. Este texto corrobora com o entendimento de diversidade utilizado pelo autor Taylor Cox Jr. (1994), que define diversidade enquanto uma coleção de diferenças e semelhanças humanas, sendo algumas observáveis e outras não. Mais recentemente, no entanto, a definição também passou a incluir características não visíveis como orientação sexual, ocupação ou status socioeconômico. Apreendida em sua dimensão cultural, a diversidade é associada aos novos movimentos sociais, especialmente os de cunho identitário, articulados em torno da defesa das chamadas "políticas de diferença" (COX JR., 1994; ALVES; GALEÃO-SILVA, 2004).

Corroborando com a definição apresentada acima, no campo da educação, as ‘agendas de diversidade’ são relacionadas às discussões de caráter mais identitário: povos indígenas, negros, quilombolas, feministas, LGBTI, povos do campo, pessoas com deficiência, povos e comunidades tradicionais, entre outros (GOMES, 2012).

Como direito à diferença, a diversidade articula-se à exigência de reconhecimento na esfera pública e política de grupos definidos como "minoritários", "subalternos", e por certas formas de feminismo. Essa reivindicação, no Brasil, partiu de alguns setores do movimento feminista e do movimento negro nos anos 1980, intensificando-se nos anos seguintes, quando passa a envolver também os movimentos indígenas e das pessoas com deficiência. (MOEHLECKE, 2009, p. 03).

Ao focalizarmos os indicadores educacionais desses grupos identitários, é possível observar que compõem os grupos mais vulneráveis em termos de aprendizagem.

\section{EDUCAÇÃO PARA TODOS E PARA CADA UM}

Atualmente, mais de 3,8 milhões de brasileiros entre 04 e 17 anos ainda estão fora da escola, sendo, em sua maioria, homens jovens, negros, com renda domiciliar de até $1 / 2$ salário mínimo per capita, moradores da zona rural e filhos de pais sem instrução ou que não completaram o Ensino Fundamental (UNICEF, 2014).

Em relação à proporção de alunwescola enfrenta mais dificuldades em produzir efeitos tanto para a retirada dos seus alunos da exclusão, quanto para a promoção destes ao nível de adequação. Uma explicação plausível que justifique a presença do fator raça como inibidor de efeitos desejáveis pode residir nas expectativas quanto ao sucesso de alunos pretos, provocando um nivelamento por baixo. (XAVIER; ALVES, 2015, p. 237). 
Outros fatores como falta de transporte escolar e bullying também compõem os indicadores de evasão escolar. De acordo com levantamento realizado em 2015 (ABGLT, 2016), estudantes lésbicas, gays, bissexuais, travestis, transexuais e intersexuais (LGBTI) relatam que são agredidos dentro das escolas e que isso atrapalha seu rendimento nos estudos:

- Entre aqueles que sofrem agressões verbais frequentemente ou quase sempre por causa da orientação sexual: 58,9\% faltaram às aulas pelo menos uma vez no último mês;

- Entre aqueles que sofrem agressões por conta da identidade de gênero - por serem travestis ou transexuais: $51,9 \%$ faltaram às aulas.

Também são percebidas diferenças no aprendizado das ciências exatas e naturais entre meninas e meninos:

No Brasil, as alunas entram na escola mais cedo, têm trajetória escolar mais regular e permanecem mais tempo na escola em comparação aos meninos. (...) Nesta pesquisa também encontramos que as meninas possuem menos chances de alcançarem o aprendizado adequado em Matemática, fato que pode ajudar a entender a baixa escolha por carreiras mais competitivas, tais como Engenharia. (XAVIER; ALVES, 2015, p. 237).

No contexto brasileiro, a abrangência territorial também se torna um desafio para assegurar que estudantes de todas as regiões tenham acesso de qualidade e de forma equânime:

Há uma enorme desigualdade, no Brasil, na distribuição de professores mais qualificados. Crianças mais pobres, que moram na zona rural, em estados do Norte e Nordeste, têm menor probabilidade de ter um professor com maior escolaridade, por exemplo. (SIMIELLI, 2017, p. 22).

Os dados apresentados acima revelam que são necessárias políticas públicas que garantam o acesso e a melhoria da qualidade do ensino para todos e para cada um, respeitando suas singularidades. A redução das desigualdades exige também medidas específicas, que permitam que determinados grupos avancem de forma mais acentuada que outros, buscando o crescimento de forma equânime.

É necessário, assim, colocar esta perspectiva no centro do planejamento de políticas públicas educacionais, com foco nas camadas menos favorecidas e mais vulneráveis da população, ultrapassando as desigualdades de gênero, cor/raça e nível socioeconômico. (EDUCATION FOR ALL \& UNESCO, 2008 apud SIMIELLI, 2017, p. 23).

Contudo, somado ao papel dos governos em propor e gerir políticas públicas específicas às populações mais vulneráveis, outros atores da sociedade também podem colaborar, direcionando investimentos para as áreas que mais precisam, levando em consideração as diferenças regionais e os contextos locais.

\section{O IMPACTO PÚBLICO DO INVESTIMENTO PRIVADO}

A recém-lançada publicação Perfil das Organizações da Sociedade Civil no Brasil, elaborada pelo Instituto de Pesquisa Econômica Aplicada (Ipea), apresenta um retrato atualizado inédito sobre o universo das 820 mil organizações da sociedade civil (OSCs) com Cadastros Nacionais de Empresas Jurídicas (CNPJs) ativos no Brasil em 2016, sendo que seis em cada dez organizações em atividade atuam com 'desenvolvimento e defesa de direitos e interesses' ou têm finalidade religiosa (IPEA, 2018). 
Essa grande diversidade do terceiro setor brasileiro também abriga as instituições de investimento social privado (ISP) ${ }^{1}$ que, segundo dados do Censo GIFE - principal indicador do setor - é formado por $53 \%$ de institutos e fundações empresariais, 19\% de instituições familiares e 14\% de organizações independentes e comunitárias. Já as empresas representam 15\% do total (GIFE, 2017).

Por sua natureza, forma de governança e gestão de recursos, as instituições do terceiro setor ${ }^{2}$ são sempre potenciais parceiras dos governos, uma vez que seu fim é o bem público e é imprescindível a relação com o governo. "Mesmo o Estado equipado com os mais abrangentes e criativos quadros da burocracia, requer essa colaboração” (IPEA, 2018, p. 9).

Com a constante preocupação de gerar impactos para a sociedade, cada vez mais institutos e fundações empresariais têm desenvolvido projetos (próprios ou de terceiros) calcados em evidências - monitoradas e avaliadas -, tendo todo o processo e resultados registrados com o intuito de ganharem escala e incidirem em políticas públicas.

Há percepção, por grande parte dos investidores sociais, de que atuar em parceria com o poder público é necessário, se não essencial (54\%), como forma de ampliar as chances de sucesso, a escala e o impacto de seus projetos (77\%), aumentar suas possibilidades de continuidade (73\%) ou conferir maior legitimidade às iniciativas (64\%). (GIFE, 2017, p. 50).

O setor público, em contrapartida, tem se mostrado bastante receptivo a essa atuação conjunta. Exemplo disso na área de educação é o Guia de Tecnologias Sociais ${ }^{3}$, desenvolvido entre 2009 e 2013 pela Secretaria de Educação Básica do Ministério da Educação (SEB/MEC), que serviu de referência para a ampliação de parcerias público-privadas de educação.

Atualmente já há uma percepção coletiva mais desenvolvida de que é impossível pensar eminvestimento social privado sem pensar no papel do Estado. O investimento social privado e a sociedade civil se organizam numa sociedade de acordo ou em interface com as políticas públicas que o Estado oferece. Dessa forma, precisamos criar instâncias intersetoriais onde estes três atores, que têm ritmo, cultura, e aspirações diferentes, possam se encontrar e formular propostas para o bem público, para aquilo que é de todos nós, mas que não é necessariamente estatal. (MONTEIRO; KISIL; WOODS, 2011, p. 44).

A publicação Perfil das Organizações da Sociedade Civil no Brasil (IPEA, 2018) indica que 4,8\% das OSCs atuam na área da educação, o equivalente a 39.669 instituições em todo o país. Ao fazer um recorte sobre as instituições do ISP, dados do último Censo GIFE (biênio 2014-2016) mostram uma quase unanimidade entre os investidores na priorização do tema: $84 \%$ das organizações afirmam investir na área da educação, ainda que atuem também em outras áreas de forma concomitante.

\footnotetext{
1 Um conceito criado nos anos 1990 por um grupo de executivos e líderes de empresas, fundações e institutos para designar uma forma de atuação social do setor privado, sobretudo empresarial, que buscava se diferenciar de formas mais tradicionais de filantropia (NOGUEIRA; SCHOMMER, 2009, p. 01). Vale destacar que ainda que o campo tenha hoje um peso corporativo importante, ele abrange organizações de diversos tipos e a presença de organizações familiares, por exemplo, tem se ampliado nos últimos anos.
}

2 Este estudo está alinhado com o conceito de 'terceiro setor' para distingui-lo do primeiro, que é o setor público, e do segundo, representado pelas atividades lucrativas, ocupando uma esfera pública não estatal e com iniciativas privadas com sentido público (CARDOSO apud IOSCHPE, 1997, p. 08).

з Mais informações em: 〈http://portal.mec.gov.br/guia-de-tecnologias〉. 
É possível observar a mesma tendência na edição 2017 da pesquisa Benchmarking do Investimento Social Corporativo $(B I S C)^{4}$ que, sobretudo no campo da educação e no atendimento à infância, indica que $67 \%$ das empresas buscam trabalhar mais próximas das organizações governamentais e alinhar seus investimentos sociais às políticas públicas: projetos são desenhados e implementados em consonância com as diretrizes de governo a partir de um diálogo sistemático com os gestores públicos, o que contribui para o alcance dos resultados previstos nas políticas governamentais (COMUNITAS, 2017).

Diferentemente do governo, por não ter compromisso com a oferta em escala, as instituições do investimento social privado têm mais liberdade de atuação e mais flexibilidade de recursos. Institutos e fundações empresariais podem, por exemplo, desenvolver projetos-piloto com pequenos grupos de estudantes mais vulneráveis, por amostra, e aplicar avaliações confrontando grupos de intervenção e grupos de controle. Por meio de parcerias com secretarias de educação, por exemplo, é possível testar, aprimorar e validar programas educacionais e depois expandir para toda rede como política pública. Essa autonomia e inovação inerentes à iniciativa privada - e suas área sociais - em muito podem contribuir com o setor público ${ }^{5}$.

Muito já se pesquisou sobre os benefícios de ambientes mais inclusivos e diversos para a aprendizagem. Estudos mostraram que quando estamos expostos a indivíduos com trajetórias distintas - portanto, ideias diferentes -, somos desafiados em nossos raciocínios, levando a um maior desenvolvimento cognitivo, pois saímos da zona de conforto e precisamos nos esforçar mais para convencer os demais de algum ponto de vista (HAWLEY; WOLF, 2016; MANTOAN, 2016; REIMERS, 2017).

Reconocer la diversidad y valorar positivamente las diferencias nos remite a un nuevo marco cultural, amplio y flexible en el que se reconozcan, respeten y acepten las múltiples singularidades. Asimismo, esta valoración influirá de forma determinante en la forma de entender la respuesta educativa que, desde el centro, se ofrece a esta diversidad. (...) Asumir la diversidad en el contexto educativo exige otra manera de entender la educación que nos lleva a trabajar por el desarrollo de la igualdad de oportunidades, la eliminación de las desigualdades y la búsqueda de nuevas formas de enfocar el proceso de enseñanza-aprendizaje. (MINISTERIO DE EDUCACIÓN DE ESPAÑA, 2012, p. 02).

Coerente com o mesmo raciocínio, outros estudos apontaram que criar ambientes apartados, ou simplesmente escolas que não valorizam a diversidade, pode, mais que não ampliar repertório, criar riscos e potenciais efeitos adversos (BARTHOLO; COSTA, 2014).

Há evidências sólidas de que a segregação escolar pode ter efeitos danosos, com impactos expressivos sobre estudantes em maior condição de desvantagem, especialmente quanto as suas aspirações de futuro, à qualidade do ensino que recebem, a sua trajetória escolar posterior, bem como provocando aumento na associação entre desempenho acadêmico e status socioeconômico. (EGGRES, 2005 apud BARTHOLO; COSTA, 2014, p. 689).

4 A pesquisa $B I S C$ é realizada em parceria entre a Comunitas e um conjunto selecionado de empresas com o objetivo de contribuir para o desenvolvimento, o aperfeiçoamento da gestão e a avaliação dos investimentos sociais corporativos no Brasil. As questões abordadas fornecem um retrato da atuação social, sendo que parte delas acompanha a metodologia utilizada nos Estados Unidos pelo Committee Encouraging Corporate Philanthropy (CECP).

5 São exemplos desse tipo de parcerias público-privadas, desenvolvidas e testadas pelo ISP e expandidas em escala pública: Projeto Jovem de Futuro (Instituto Unibanco) e Olimpíada de Língua Portuguesa (Fundação Itaú Social). 
Contudo, como apontado no artigo de abertura do Censo GIFE 2016, Um olhar sobre a diversidade no investimento social privado (GIFE, 2017), apenas $2 \%$ dos investidores sociais consideram diferenças raciais e $4 \%$ levam em conta as diferenças de gênero como características dos beneficiários de pelo menos um de seus três projetos ou programas principais.

Em um dos países mais desiguais do mundo e com uma enorme diversidade racial, esse dado chama atenção, principalmente porque a desigualdade possui uma forte relação com esses dois recortes. (SAEZ; SANTIAGO, 2017, p. 25).

\section{Gráfico 1: Áreas de atuação dos investidores sociais brasileiros}

\section{NAS ORGANIZAÇÕES}

NOS PROJETOS *

Comunicação

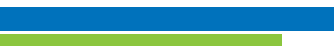

Saúde

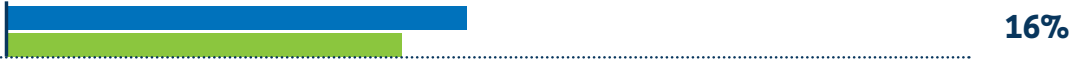

Assistência social

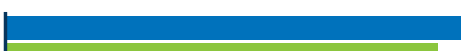

$19 \%$

Defesa de direitos

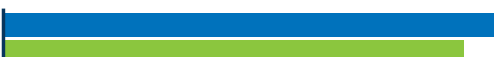

$19 \%$

Esporte e recreação

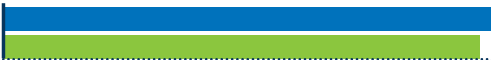

$17 \%$

Geração de trabalho e renda

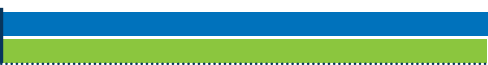

$18 \%$

Desenvolvimento comunitário

Meio ambiente

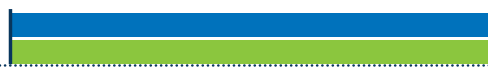

Apoio à gestão de OSCs

$23 \%$

Cultura e artes

$28 \%$

Formação de jovens para trabalho

Educação

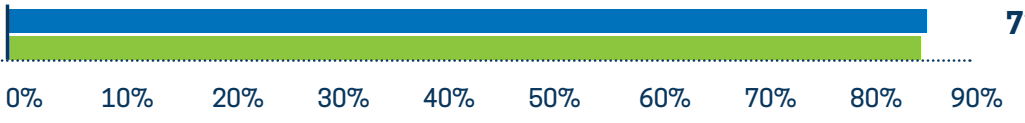

2014

2016

FONTE: GIFE, 2017

* Informação referente apenas ao ano de 2016. 


\section{Gráfico 2: Características dos beneficiários levadas em consideração nos projetos mais representativos}

Idade
Sexo, gênero ou orientação sexual
Outros tipos de atributos
Grupos étnicos, raciais, religiosos ou povos /
comunidades tradicionais
Pessoas com deficiência

FONTE: GIFE, 2017

É possível constatar que pouco se avançou em relação à base anterior: no Censo GIFE 2014 (GIFE, 2015), mais da metade (52\%) dos programas com foco em educação definem seus beneficiários diretos como sendo as crianças, os adolescentes, os jovens e os adultos educandos que participam das iniciativas realizadas ou apoiadas pelas organizações respondentes.

Com efeito, nenhum dos programas com foco em educação elencados pelos respondentes do Censo GIFE 2014 leva em consideração o gênero dos educandos como critério de participação, apenas dois consideram o fator cor/raça e somente três levam em conta a condição física e mental na definição de seus beneficiários. (LIMA, 2015, p.30).

O mesmo pode ser observado entre as empresas respondentes da pesquisa BISC 2017, cujas políticas públicas priorizadas são: $67 \%$ educação de qualidade para todos; $67 \%$ promoção, proteção e defesa dos direitos humanos de crianças e adolescentes; $62 \%$ esporte, cidadania e desenvolvimento, $58 \%$ desenvolvimento regional e territorial; $50 \%$ qualidade ambiental. Ações voltadas à valorização da diversidade aparecem com percentuais menores, sendo que merecem destaque (COMUNITAS, 2017):

- 25\%: "Políticas para as mulheres: promoção da igualdade e enfrentamento à violência";

- 17\%: "Promoção da igualdade racial e superação do racismo";

- 17\%: "Promoção e defesa do direito de pessoas com deficiência".

\section{DIVERSIDADE NA GESTÃO, DIVERSIDADE NOS PROJETOS}

Em junho de 2017, um artigo de opinião assinado por Neca Setubal e José Marcelo Zacchi ${ }^{6}$ e publicado

6 Presidente do Conselho de Governança e secretário-geral do Grupo de Institutos, Fundações e Empresas (GIFE), respectivamente. 
no jornal paulista $O$ Estado de S. Paulo destacava a contribuição que os institutos e fundações empresariais poderiam dar às suas respectivas empresas mantenedoras quanto a inclusão e promoção da diversidade a partir da experiência de seus programas e projetos sociais:

As empresas deparam-se com o debate sobre gênero, relações étnico-raciais, inserção de pessoas com deficiência, temas complexos com os quais o alinhamento com as iniciativas do investimento social pode gerar uma ampla contribuição, com base em suas experiências em programas e projetos focados na garantia de direitos (SETUBAL; ZACCHI, 2017).

No entanto, como já visto, investimentos em 'agendas de diversidade' ainda não são uma realidade entre os associados ao GIFE. Nesse sentido, este artigo lança como hipótese o fato de que os baixos investimentos em educação com ênfase em diversidade possam estar relacionados à pouca diversidade nos conselhos de administração dos institutos e fundações empresariais, conforme indicado pelo último Censo GIFE:

\section{Quadro 1: Diversidade na gestão do ISP no Brasil}

\begin{tabular}{|c|c|}
\hline Gênero & Raça e Etnia \\
\hline $\begin{array}{l}\text { - } 49 \% \text { dos institutos e fundações possuem } 75 \% \text { ou } \\
\text { mais de conselheiros homens; } \\
\text { - } 21 \% \text { possuem somente conselheiros homens; } \\
\text { - Dos } 873 \text { conselheiros dos respondentes, apenas } 24 \% \\
\text { são mulheres; } \\
\text { - } 48 \% \text { dos colaboradores dos respondentes são mulhe- } \\
\text { res. }\end{array}$ & $\begin{array}{l}\text { - } 71 \% \text { dos institutos e fundações possuem apenas } \\
\text { conselheiros brancos; } \\
\text { - } 16 \% \text { das organizações possuem somente conselhei- } \\
\text { ros pardos; } \\
\text { - Somente } 3 \% \text { possuem conselheiros negros; } \\
\text { - } 2 \% \text { possuem conselheiros indígenas. }\end{array}$ \\
\hline
\end{tabular}

FONTE: GIFE, 2017. Elaboração própria

A baixa presença de negros e mulheres nos conselhos das organizações de investimento social privado também não contribui para que esse olhar esteja mais presente no ISP. (SAEZ; SANTIAGO, 2017, p. 26).

Apesar de não trazer informações separadas por membros da gestão, conselhos e equipes, a partir dos dados da publicação Perfil das Organizações da Sociedade Civil no Brasil (Ipea, 2018) é possível constatar que o mercado de trabalho para profissionais das OSCs apresenta desigualdades similares ao do mercado de trabalho 'comercial', inibindo assim um ambiente mais diversificado e heterogêneo. Segundo levantamento realizado em 2015:

- 65\% das pessoas empregadas em OSCs são mulheres e recebiam, em média, 85\% do salário de homens;

- $63 \%$ das pessoas ocupadas nas entidades são brancas e 37\% negras;

- a contratação de pessoas com deficiência varia de modo significativo em OSCs de diferentes finalidades e entre grupos de uma mesma finalidade.

A presença e o incentivo de diversidade tanto nas equipes e conselhos, quanto nos projetos desenvolvidos/apoiados por institutos e fundações empresariais é fator que precisa entrar na pauta e também está presente no debate em outros países.

Divulgado em 19 de julho de 2018, o novo relatório de pesquisa Esforços de Diversidade Sem Fins Lucrativos: Práticas Atuais e o Papel das Fundações (tradução livre), desenvolvido pelo Center for Effective 
Philanthropy (CEP), compartilha perspectivas de organizações sem fins lucrativos sobre a diversidade em seu trabalho e quais são suas necessidades. Foram ouvidos 338 CEOs de organizações sem fins lucrativos de todo os Estados Unidos - com despesas anuais que variam de US\$100 mil a US\$ 100 milhões - sobre a diversidade em suas instituições e como as fundações podem ser mais efetivas nessa área. Segundo o relatório, os respondentes reconhecem que há espaço para melhorias em termos de quão diversificados eles acreditam que suas equipes e diretorias devem ser para atingir os objetivos de sua organização versus quão diversificados são atualmente, assim como reconhecem a necessidade de refletir melhor sobre as populações atendidas.

\section{Quadro 2: Auto avaliação quanto à diversidade racial e de pessoas com deficiência}

\begin{tabular}{|c|c|}
\hline Raça e Etnia & Pessoas com Deficiência \\
\hline $\begin{array}{l}\text { - } 79 \% \text { dos CEOs de entidades sem fins lucrativos ava- } \\
\text { liam sua organização como pelo menos um pouco diver- } \\
\text { sificada; } \\
\text { - Apenas } 17 \% \text { classificam sua organização como extre- } \\
\text { mamente diversa; } \\
\text { - } 85 \% \text { avaliam que sua organização reflete as popula- } \\
\text { ções que procuram servir, pelo menos um pouco, em } \\
\text { raça e etnia; } \\
\text { - Cerca de } 1 / 4 \text { acredita que refletem muito bem a popu- } \\
\text { lação que procuram servir. }\end{array}$ & $\begin{array}{l}\text { - } 59 \% \text { acreditam que sua organização não é muito diver- } \\
\text { sificada ou não é de todo diversificada quando se trata } \\
\text { de deficiência; } \\
\text { - } 60 \% \text { dos CEOs de entidades sem fins lucrativos } \\
\text { acham que suas organizações refletem as populações } \\
\text { que procuram servir, pelo menos um pouco, quando se } \\
\text { trata de deficiência; } \\
\text { - Apenas } 11 \% \text { dos CEOs das entidades sem fins lucra- } \\
\text { tivos acreditam que suas organizações estão refletindo } \\
\text { as populações que procuram atender muito bem quan- } \\
\text { do se trata de deficiência. }\end{array}$ \\
\hline
\end{tabular}

FONTE: GIFE, 2017. Elaboração própria

Em maio de 2014, a Associação de Executivos da Black Foundation (ABFE), em parceria com a Rede Filantrópica Negra, divulgou o relatório Entrevista de saída: percepções sobre por que os profissionais negros deixam as instituições de doação ${ }^{7}$ (tradução livre), no qual destaca a necessidade de canais de liderança, programas de desenvolvimento e estratégias de retenção eficazes voltadas aos profissionais afro-americanos no campo da filantropia.

Jessica Christoffel $(2017)^{8}$ investigou os benefícios potenciais da diversidade nos membros do conselho de administração de organizações sociais, na medida em que as ideias inovadoras e perspectivas podem se traduzir em ganhos relacionados ao negócio para a organização. A partir de uma revisão bibliográfica e teorias que discutem a diversidade nos quadros, o artigo mostrou um exemplo em que a diversidade do conselho era a principal diferença entre duas organizações sem fins lucrativos cuja missão, localização e contexto eram praticamente as mesmas.

Controladas as diferenças de escopo, os resultados mostraram que o conselho mais diversificado foi mais eficiente com seus gastos gerais, captação de recursos e gastos com programas. Segundo o artigo, para organizações sem fins lucrativos, a conquista de sua missão/propósito é seu objetivo principal e as ideias inovadoras dos membros contribuíram para trazer/captar recursos de forma mais eficiente.

7 Mais informações em: <https://www.nebip.org/>.

8 Jessica Christoffel é pesquisadora na University at Albany, State University of New York. 


\section{CONSIDERAÇÕES FINAIS}

A literatura indica os ganhos de aprendizagem em ambientes que reúnem estudantes com perfis e habilidades diferentes, em que todos são estimulados a conviver e valorizar as diferenças. Contudo, os dados coletados pelo Censo GIFE e nas pesquisas do Ipea (2018) e BISC (COMUNITAS, 2017) demonstram que institutos e fundações empresariais ainda investem pouco em ações e projetos dessa natureza, até porque a composição de suas equipes e conselhos de governança também não refletem essa preocupação. Dessa forma, o perfil homogêneo dos conselhos de administração dessas instituições é um dado que talvez explique a não priorização das agendas de diversidade em projetos de educação desenvolvidos/financiados pelo ISP brasileiro.

Partindo da premissa de que há interesse dos investidores sociais e receptividade dos governos em contribuir para a melhoria da educação pública, este artigo buscou refletir como o investimento social privado pode contribuir com a valorização da diversidade nas políticas públicas brasileiras de educação.

Esse não é um desafio apenas brasileiro: as pesquisas internacionais aqui apresentadas demonstram que, apesar de reconhecerem como uma lacuna, ainda são poucas as organizações sociais com membros do conselho de governança refletindo a diversidade da sociedade. No entanto, quando o fazem, podem gerar contribuições positivas e mais efetividade (financeira).

Criar soluções e formatos inovadores para incluir o olhar das desigualdades de gênero e raça nos programas, projetos e soluções sociais pode ser uma grande contribuição do ISP para o país (SAEZ; SANTIAGO, 2017, p. 26).

Como encaminhamentos futuros, no contexto das organizações sociais brasileiras, sugere-se que este tema esteja em discussão constante, especialmente nas instituições representativas: Rede Temática de Gestão Institucional do GIFE, Rede de Fundos Independentes para a Justiça Social e Associação Brasileira de ONGs (Abong). No âmbito acadêmico, observou-se uma lacuna de estudos mais detalhados dos indicadores do ISP a partir de cruzamentos das edições do Censo GIFE, por exemplo, no que a $1^{\text {a }}$ chamada de artigos acadêmicos promovida pelo GIFE certamente contribuirá. 


\section{REFERÊNCIAS BIBLIOGRÁFICAS}

ALVES, Mário Aquino; SILVA, Luis Guilherme Galeão. A crítica da gestão da diversidade nas organizações. Revista de Administração de Empresas, São Paulo: v. 44, n. 3, p. 20-29.

ASSOCIAÇÃO BRASILEIRA DE GAYS, LÉSBICAS, BISSEXUAIS, TRAVESTIS, TRANSEXUAIS E INTERSEXOS (ABGLT). Pesquisa Nacional sobre o Ambiente Educacional no Brasil 2015: as experiências de adolescentes e jovens lésbicas, gays, bissexuais, travestis e transexuais em nossos ambientes educacionais. Curitiba: ABGLT; Secretaria de Educação. 2016.

ASSOCIATION OF BLACK FOUNDATION EXECUTIVES (ABFE). The Exit Interview: Perceptions on Why Black Professionals Leave Grantmaking Institutions. New York: ABFE. 2014. Disponível em: 〈https://goo.gl/QJGTjH〉. Acesso em: 20 nov. 2018.

BARTHOLO, Tiago Lisboa; COSTA, Marcio da. Turnos e segregação escolar: discutindo as desigualdades intraescolares. Cadernos de Pesquisa, v. 44, n. 153, p. 670-692, 2014. Disponível em: 〈https://bit.ly/2DXEuIG〉. Acesso em: 20 nov. 2018.

CHRISTOFFEL, Jessica. Literature Review and Accompanying Analysis of Diversity on a Nonprofit's Board of Directors: Does Diversity Impact Organizational Effectiveness? University at Albany; 2017. Disponível em: 〈https://goo.gl/ZJNaZv〉. Acesso em: 06 set. 2018.

COMUNITAS. Benchmarking do Investimento Social Corporativo (BISC). São Paulo: Comunitas, 2017. Disponível em: <https://bit.ly/2Re1beR>. Acesso em: 20 nov. 2018.

COX JR., Taylor. Cultural Diversity in Organizations: Theory, Research and Practice. 2. ed. San Francisco: Berrett Koehler, 1994.

FUNDO INTERNACIONAL DE EMERGÊNCIA PARA A INFÂNCIA DAS NAÇÕES UNIDAS (UNICEF). O enfrentamento da exclusão escolar no Brasil. Brasília: UNICEF; Campanha Nacional pelo Direito à Educação. 2014. Disponível em: <https:// goo.gl/8CQqLb>. Acesso em: 20 nov. 2018.

GOMES, Nilma Lino. Desigualdades e diversidade na educação. Educação \& Sociedade, v.33, n.120, 2012.

GRUPO DE INSTITUTOS, FUNDAÇÕES E EMPRESAS (GIFE). Censo GIFE 2014. São Paulo: GIFE, 2015. 160 p. Disponível em: 〈https://bit.ly/2r26jqX>. Acesso em: 20 nov. 2018.

Censo GIFE 2016. São Paulo: GIFE, 2017. 256 p. Disponível em: <https://bit.ly/2LYsq9u>. Acesso em: 20 nov. 2018.

HAWLEY, Willis D; WOLF, Rebecca. Diversity Responsive Schools. Southern Poverty Law Center, 2016. Disponivel em: <https://goo.gl/CMUQQ9>. Acesso em: 15 out. 2017.

INSTITUTO DE PESQUISA ECONÔMICA APLICADA (IPEA). Perfil das organizações da sociedade civil no Brasil. LOPEZ, Felix Garcia (Org.). Brasília: Ipea, 2018. 176 p.

IOSCHPE, Evelyn Berg (Org.) Terceiro Setor: Desenvolvimento Social Sustentado. Rio de Janeiro: Paz e Terra. 1997.

LIMA, Ana Lúcia d’Império. A aposta do investimento social privado na educação. In: . Censo GIFE 2014. São Paulo: GIFE, 2015. p. 27-34.

MANTOAN, Maria Teresa Egler. O Desafio das Diferenças nas Escolas. Vozes. 2016.

MINISTERIO DE EDUCACIÓN DE ESPAÑA. Educación Inclusiva. Iguales en la Diversidad - Módulo 2: Clarificar nuestros valores. Igualdad em la Diversidad. Disponível em: 〈https://goo.gl/FHVPzC〉. Acesso em: 20 nov. 2018. 
MOEHLECKE, Sabrina. As políticas de diversidade na educação no governo Lula. Cadernos de Pesquisa. São Paulo, v. 39, n. 137, 2009. Disponível em: 〈https://goo.gl/wqLBPv〉. Acesso em 20 nov. 2018.

MONTEIRO, Helena; KISIL, Marcos; WOODS, Márcia. Tendências do Investimento Social Privado na América Latina. São Paulo: Imprensa Nacional. 2011. 44 p.

NOGUEIRA, Fernando do A.; SCHOMMER, Paula Chies. Quinze Anos de Investimento Social Privado no Brasil: Conceito e Práticas em Construção. In: Anais do XXXIII Encontro da ANPAD. São Paulo: Anpad, 2009. Disponível em: <https://idis. org.br/wp-content/uploads/2009/11/ISP_15_anos.pdf> Acesso em: 20 nov. 2018.

REIMERS, Fernando. Educacion para todos: um estudiante a la vez. Paperback. 2017.

SAEZ, Erika; SANTIAGO, Graziela. Um olhar sobre a diversidade no Investimento Social Privado. In: Censo GIFE 2016. São Paulo: GIFE, 2017. p. 22-31.

SETUBAL, Neca; ZACCHI, José Marcelo. Investimento social privado: seus desafios e oportunidades em tempos de crise. É tempo de unir esforços. O Estado de São Paulo. São Paulo, 2017. Disponível em: 〈https://goo.gl/bdfa4e〉.

SIMIELLI, Lara Elena Ramos. Equidade e oportunidades educacionais: O acesso a professores no Brasil. Archivos Analíticos de Políticas Educativas, v. 25, 46 p., 2017.

THE CENTER FOR EFFECTIVE PHILANTHROPY (CEP). Nonprofit Diversity Efforts: Current Practices and the Role of Foundations. Cambridge: Center for Effective Philanthropy. 2018.

XAVIER, Flávia P.; ALVES, Maria Tereza G. A composição social importa para os efeitos das escolas no ensino fundamental? Estudos em Avaliação Educacional. 2015. p. 216-242. 



\section{OS AUTORES}

\section{Mário Aquino Alves}

Possui mestrado e doutorado em Administração de Empresas pela Fundação Getúlio Vargas - SP e pós-doutorado na HEC Montréal. É pesquisador 1D do CNPq e editor dos Cadernos Gestão Pública e Cidadania. Coordena os cursos de mestrado e doutorado em Administração Pública e Governo da FGV EAESP.

\section{Andréa Martini Pineda}

É graduada em Comunicação e mestra em Linguística Aplicada, ambos pela PUC-SP. Atualmente é doutoranda em Administração Pública e Governo na Fundação Getúlio Vargas e assistente de pesquisa no Centro de Estudos em Administração Pública e Governo da FGV EAESP. 


\title{
artigos GIFE
}

\author{
Supervisão: José Marcelo Zacchi e Erika Sanchez Saez \\ Coordenação: Graziela Santiago \\ Suporte: Carolina Magosso \\ Comitê de seleção: Ana Lúcia D'Império Lima, \\ Aron Belinky, Beatriz Azeredo e Paula Galeano \\ Projeto gráfico e diagramação: Dafne Rozencwaig Souza \\ Revisão: Amanda Proetti \\ Impressão: Forma Certa
}

(C) 2019 GIFE - Grupo de Institutos Fundações e Empresas

DOI: doi.org/10.4322/978-85-88462-37-3-01

\section{(c) (P) 6}

Este material é disponibilizado sob a licenca Creative Commons Atribuição Não Comercial 4.0 Internacional. http://creativecommons.org/licenses/by-nc/4.0

As opiniões e análises expressas nesta publicação não necessariamente refletem as do GIFE. 